\title{
Analisis Penggunaan Model Inkuiri Untuk Mengetahui Kemampuan Representasi Verbal Dan Matematis Dalam Pembelajaran Fisika Di SMA
}

\author{
Ilham Mubarok, Nana \\ Pendidikan Fisika, Fakultas Keguruan Dan Ilmu Pendidikan \\ Universitas Siliwangi
}

Email responden: ilhammubarok05@gmail.com , corresponden: nana@unsil.ac.id

\begin{abstract}
The purpose of this study was to determine the use of inquiry model physics learning in high school students on verbal and mathematical representation skills. In learning physics, it is necessary to have knowledge of basic theory and its application, so it is not just knowing mathematical formulas and doing math problems. This writing is designed as a literature study research by reviewing several sources to be studied and made conclusions. The results of the study found that the verbal representation ability of students who used the inquiry model was included in the high category, while the verbal representation ability of students who did not use the inquiry model was included in the medium category. The mathematical representation ability of students who use the inquiry model and those who do not use the inquiry model are included in the high category. Thus, it is necessary for students to be prepared to accept various learning methods.
\end{abstract}

Keywords: inquiry model, verbal representation, mathematical

Abstrak: Tujuan penelitian ini untuk mengetahui penggunaan pembelajaran fisika model inkuiri pada siswa SMA pada kemampuan representasi verbal dan matematis. Pada pembelajaran fisika perlu adanya pengetahuan teori dasar dan aplikasinya, jadi tidak hanya sekedar mengetahui rumus-rumus matematika dan mengerjakan soal matematika. Penulisan ini didesain sebagai penelitian studi literature dengan mengkaji beberapa sumber untuk dikaji dan dibuat kesimpulan. Hasil penulisan mendapatkan bahwa kemampuan representasi verbal siswa yang menggunakan model inkuiri inkuiri termasuk dalam kategori tinggi, sedangkan kemampuan representasi verbal siswa yang tidak menggunakan model inkuri termasuk dalam kategori sedang. Kemampuan representasi matematis siswa yang menggunakan model inkuiri dan yang tidak menggunakan model inkuiri termasuk dalam kategori tinggi. Dengan demikian, perlu adanya kesiapan siswa dalam menerima berbagai metode pembelajaran.

Kata Kunci: model inkuiri, representasi verbal, matematis

\section{Pendahuluan}

Ilmu pengetahuan, matematika dan disiplin teknis memiliki kepentingan kunci untuk kelanjutan percepatan pengembangan ilmiah dan teknis masyarakat. Terlepas dari 
pentingnya disiplin ilmu ini untuk pengembangan minat masyarakat muda dalam belajar matematika dan sains turun dan jumlah siswa yang ingin belajar sains dan universitas teknik menurun. Banyak penelitian yang menyoroti penurunan yang mengkhawatirkan dalam minat anak muda untuk belajar sains, matematika, dan informatika. Pembalikan praktik sekolah dari metode deduktif menjadi berbasis inkuiri menyediakan sarana untuk meningkatkan minat siswa dalam sains dan matematika (Lukáč \& Sekerák, 2016).

Pengajaran berbasis inkuiri mendorong rasa ingin tahu dan observasi diikuti dengan eksperimen, pemodelan, pemecahan masalah, penjelasan dan pembenaran temuan. Penelitian sebelumnya telah menunjukkan bahwa pengajaran matematika berbasis inkuiri meningkatkan pemahaman siswa, pemikiran matematika dan keterampilan pemecahan masalah (Lukáč \& Sekerák, 2016).

Mata pelajaran fisika merupakan pelajaran mengandung konsep-konsep yang dapat direpresentasikan pada bentuk verbal, fisis, gambar dan matematis (Guntara \& Nona, 2019). Proses belajar Fisika bersifat pada menentukan konsep, prinsip, teori, dan hukumhukum alam, dan juga untuk dapat menimbulkan reaksi, atau jawaban yang bisa dipahami dan diterima secara objektif, jujur dan rasional (Habibah \& Bunawan, 2018).

Model pembelajaran Inquiry merupakan cara pembelajaran yang mengajarkan kepada siswa untuk menjadi kritis, analisis argumentatif dalam mencari jawaban-jawaban berbagai permasalahan yang ada di alam, melalui pengalaman-pengalaman dan sumber lainnya. Pada dasarnya inquiry adalah sautu perluasan proses discovery (penemuan) dalam cara yang lebih dewasa, sebagai tambahan pada proses discovery, Inquiry mengandung proses-proses mental yang lebih tinggi tingkatannya (Nana \& Pramono, 2019).

Data yang sudah dikaji berdasarkan hasil observasi yang dilakukan oleh (Guntara \& Nona, 2019) bahwa pada pembelajaran masih adanya menggunakan penjelasan verbal dalam menyampaikan konsep-konsep fisika dan minim menggunakan representasi lain seperti halnya matematis. Dan juga, pada penyelesaian soal-soal fisika lebih terarahkan pada penggunaan rumus tanpa melakukan proses investigasi ataupun kegiatan praktikum.

Untuk mencegah proses pembelajaran seperti disebutkan tadi maka perlu dilaksanakan model pembelajaran inkuiri, untuk memperbaharui proses belajar siswa. Penerapan model inkuiri akan menciptakan kegiatan pembelajaran yang lebih menyenangkan dan akhirnya berpengaruh pada pemahaman konsep yang ditemukan (Juniati \& Widiana, 2017). 


\section{METODE}

Metode yang digunakan dalam penulisan ini berupa literature review. Data dikumpulkan dari beberapa sumber seperti google scholar. Setelah terkumpul, dilanjut untuk dianalisis kemudian disajikan dalam hasil dan pembahasan agar dapat dibuat kesimpulan.

\section{HASIL DAN PEMBAHASAN}

\subsection{Model Inkuri}

Model inkuiri adalah model yang meliputi keterampilan proses yang terdapat pengamatan, mengumpulkan, mengorganisasi data, mengidentifikasi, mengontrol variabel, menguji, merumuskan hipotesism serta keterampilan menjelaskan dan inferensi. Pembelajaran inkuiri ketika diterapkan maka dapat menumbuhkan aspek keterampilan seperti menyusun laporan siswa, hal ini sepakat dengan pernyataan yang dikemukakan oleh (Bilqin, 2009) yang menyatakan bahwa aktifitas pembelajaran menggunakan inkuiri terbimbing akan membantu siswa ketika mengembangkan rasa tanggung jawab individu, kognitif, problem solving, serta kemampuan pemahaman.

Dengan metode pembelajaran inkuiri akan melatih siswa untuk berani mengemukakan pendapat dan menemukan sendiri pengetahuannya yang berguna untuk memecahkan masalah. Penggunaan metode pembelajaran inkuiri secara efisien dan efektif akan mengurangi monopoli guru dalam menguasai jalannya proses pembelajaran, dan kebosanan siswa dalam suatu pelajaran akan berkurang (Andrini, 2016).

\subsection{Representasi Verbal}

Representasi verbal adalah bentuk untuk menyampaikan definisi dari konsep. Seseorang yang memiliki kemampuan penglihatan representasi yang bagus akan menunjukan hubungan antara gambar terhadap strategi penyelesaian dalam berbagai masalah matematika (Murtianto, Suhendar, \& Sutrisno, 2019).

Representasi verbal adalah: 1) membuat situasi masalah berdasarkan data atau representasi yang diberikan,2) menuliskan interpretasi dari suatu representasi,3) menuliskan langkah-langkah penyelesaian masalah matematika dengan kata-kata, 4) menyususn cerita yang sesuai dengan suatu representasi yang disajikan, dan 5) menjawab soal dengan menggunakan kata- kata atau tertulis.

\subsection{Representasi matematis}

Pentingnya representasi matematis dan kemampuan penalaran ini perlu mendapat perhatian dalam pembelajaran matematika di perguruan tinggi. Pendidik harus mampu menciptakan suatu pembelajaran yang mampu memfasilitasi peserta 
didik calon pendidik untuk mengembangkan kemampuan representasi dan penalaran matematisnya. Untuk itu, pendidik perlu mencari sebuah model pembelajaran yang tepat agar peserta didik terbiasa untuk merepresentasikan suatu ide secara matematis sehingga kelak dapat menjadi pendidik yang dapat memberikan pembelajaran yang berkualitas bagi peserta didik di sekolah (Nurfitriyanti et al., 2020).

\subsection{Penggunaan Model Inkuiri Untuk Mengetahui Kemampuan Representasi Verbal dan Matematis Dalam Pembelajaran Fisika Di SMA}

Berdasarkan beberapa sumber yang dikaji dapat disimpulkan penggunaan model inkuiri untuk mengetahui kemampuan representasi verbal dan matematis dalam pembelajaran fisika di sma menyatakan bahwa Kemampuan representasi verbal siswa yang menggunakan model inkuiri inkuiri termasuk dalam kategori tinggi, sedangkan kemampuan representasi verbal siswa yang tidak menggunakan model inkuri termasuk dalam kategori sedang. Kemampuan representasi matematis siswa yang menggunakan model inkuiri dan yang tidak menggunakan model inkuiri termasuk dalam kategori tinggi.

\section{PENUTUP}

Berdasarkan hasil dan pembahasan, dapat diperoleh kesimpulan antara lain Model inkuiri dapat meningkatkan kemampuan representasi verbal, matematis dan hasil belajar siswa. Kemampuan representasi verbal siswa yang menggunakan model inkuiri inkuiri tergolong tinggi, sedangkan kemampuan representasi verbal siswa yang tidak menggunakan model inkuri tergolong sedang. Kemampuan representasi matematis siswa yang menggunakan model inkuiri inkuiri dan yang tidak menggunakan model inkuiri tergolong tinggi.

\section{UCAPAN TERIMA KASIH}

Terima kasih kepada semua pihak yang telah membantu demi kesempurnaan artikel ini menjadi lebih baik.

\section{DAFTAR PUSTAKA}

Bilqin, I. (2009). The Effects Of Guided Inquiry Instruction Incorporating A Cooperative Learning Approach On University Students' Achievement Of Acid And Bases Concepts And Attitude Toward Guided Inquiry Instruction. Scientific Research And, 1038-1046.

Guntara, Y., \& Nona, M. M. (2019). Integrasi Inquiry Training: Pengembangan Physics Subject Specific Pedagogy Untuk Meningkatkan Kemampuan Representasi 
Matematis Siswa Sma. Gravity : Jurnal Ilmiah Penelitian Dan Pembelajaran Fisika, 14.

Habibah, S., \& Bunawan, W. (2018). Implementasi Pendekatan Multi Representasi Pada Model Pembelajaran Inquiry Training Untuk Meningkatkan Hasil Belajar Siswa Pada Materi Pokok Usaha Dan Energi. Jurnal Penelitian Bidang Pendidikan, 29. Juniati, W., \& Widiana, W. (2017). Penerapan Model Pembelajaran Inkuiri Untuk Meningkatkan Hasil Belajar Ipa. Jurnal Ilmiah Sekolah Dasar, 22.

Lukáč, S., \& Sekerák, J. (2016). Impact Of Inquiry Approaches To Mathematics Teaching On The Development Of Skills To Analyse And Interpret Relationships Between Variables. Icte Journal, 6.

Murtianto, H. Y., Suhendar, A., \& Sutrisno. (2019). Analisis Kemampuan Representasi Verbal Siswa Dalam Pemecahan Masalah Matematika Berdasarkan Tahapan Krulik Dan Rudnick Ditinjau Dari Motivasi Belajar Siswa. Jurnal Ilmiah Pendidikan Matematika, 78.

Andrini, V. S. (2016). The Effectiveness of Inquiry Learning Method to Enhance Students 'Learning Outcome: A Theoritical and Empirical Review. Journal of Education and Practice, 7(3), 38-42.

Nana, N., \& Pramono, H. (2019). Upaya Peningkatan Kemampuan Kognitif dan Komunikasi Ilmiah Siswa Kelas X MIA 1 SMA Negeri 1 Ciamis Menggunakan Model Pembelajaran Inquiry. Diffraction, 1(1).

Nurfitriyanti, M., Rita Kusumawardani, R., \& Lestari, I. (2020). Kemampuan Representasi Matematis Peserta Didik Ditinjau Penalaran Matematis pada Pembelajaran Berbasis Masalah. Jurnal Gantang, 5(1), 19-28. https://doi.org/10.31629/jg.v5i1.1665 